\title{
Language Style Used by Tony Stark in the Avengers: Infinity War
}

\author{
Ida Ayu Vivin Indah Sari.S, Nyoman Udayana, I Gusti Ngurah Parthama \\ English Department, Faculty of Humanities, Udayana University \\ Denpasar, Bali, Indonesia \\ idaayuvivin4@gmail.com
}

\begin{abstract}
Language styles create many impressions in the spoken form and writing. Therefore, language style becomes a form of inner expression that is typical of a speaker of the language. A person usually chooses a word or sentence in such a way as to achieve a specific goal for the listener. This study aimed to discuss the language style and its function that was used by Tony Stark in the Avengers: Infinity War movie. The discourse of Tony Stark in Avengers: Infinity War movie was taken as the data for this study. The data has collected by observing and taking note of the conversation of Tony Stark and other characters. It was analyzed by the Sociolinguistic theory from Holmes (2004). Based on the data analysis, the result shows that Tony Stark used more standard language to communicate with his Avengers partners. It is because this movie had a genre of action-science fiction that made Tony Stark face more serious and formal situations. There were also found five functions of language styles used by Tony Stark, there are expressive function, directive function, referential function, phatic function, and poetic function.
\end{abstract}

Keyword: sociolinguistic, language style, the function of language.

\section{INTRODUCTION}

Language style creates many impressions in the spoken form and writing. Conversation, speech, storytelling, discourse, radio, and television broadcasts all fit into the category of spoken language. Meanwhile, written language is any utterance that is written, such as novels, comics, newspapers, magazines, letters, books, journals, and essays therefore, language style becomes a form of inner expression that is typical of a speaker of the language. According to Chaika (1982:29) style refers to the selection of the linguistic forms to convey social or artistic effects. The style also acts as a set of instructions. In this case, style determines how a speaker interacts and how the listener recognizes the communication appropriately; whether serious, funny, questionable or in some other context. Besides, the language that is delivered by a speaker also has its function. Language function aims to make the hearer understand the meaning of the language and there is no misunderstanding between speaker and hearer.

There have been some similar studies conducted in the past. The writer read some previous researches as an example and literature review to perform this study. Those previous researches have their specifications relevant to the topic and object of the research.
The first article thesis was written by Rahayu (2018) entitled Language Style Used by Fangirls in Korean Idol Community. This study aims to identify the language style used by the fangirls in the Korean idol community and their jargon that is frequently used in the community.

The second article thesis was done by Tololiu (2017) and her study entitled Language Style Concerning The Movie Ella Enchanted by Gail Carson Levine. This study explains about types of language style in Ella Enchanted movie and the factors influencing the use of language style in that movie.

The third article thesis was written by Dewi (2020) entitled Language Style Used by Main Character in Movie Me Before You. This study concentrates on analyzing the types of language style and also the language function used by the main character in "Me Before You" movie.

The fourth article was written by Dong (2016) entitled Formality and Maturity of the Artist - Stylistic Analysis of a Poem Joyce's A Portrait of the Artist as a Young Man. This study aims to identify the language style used in the poem Joyce's A Portrait of the Artist as a Young Man and to analyze the stylistic analysis terms of language levels of lexicology, grammar, and phonology.

The last article was done by Rashid (2013) entitled $A$ Contrastive Study of Language Style as-Tawkid between Malay and Arabic. This study aims to analyze the language 
style and similarity-differences of Malay and Arabic because some students are confused and do not understand Arabic grammar as it contains complex terminology to be understood.

Since the 1900s, the movie has become one of the best influences on people's lives. Whether the fashion, language style, the storyline is all very interesting to be a trend by the people in each era. One of the most influential things in the movie is language style. In this study, the language style used by Tony Stark in Avengers: Infinity War was selected as the object. Tony Stark and also known as Iron Man is one of the main characters that bring the Marvel Cinematic Universe as a famous series all around the world.

Based on the background of the study, the problem of study are:

1. What types of language styles are used by Tony Stark in Avengers: Infinity War movie?

2. How does the function of language style used in this movie?

The aims of this study are:

a. To identify the types of language style that are used by Tony Stark in the movie Avengers: Infinity War

b. To describe the function of language style that is used by Tony Stark in Avengers: Infinity War movie

\section{Material ANd Method}

Avengers: Infinity War movie was used as the data source. The Avengers is a superhero movie based on the Marvel Comics superhero team of the same name. Marvel Studios produced the film, which was distributed by Walt Disney Studios Motion Pictures. Tony Stark discourse was selected as the data for two reasons. First, Tony Stark is an important character in this movie. Second, this movie and also Tony Stark's (Iron Man) character has a lot of fans.

The method applied to collect the data was the observation method. The observation method was appropriate for this study of library research. The technique of collecting the data was done by using the following steps. First, observing the data was done by watching the movie and reading the movie's subtitles. Second, note-taking of the subtitles which are considered as a type of language style. Then, the researcher chose which sentences are suitable for analysis.

Descriptive qualitative was selected as the method of analyzing data. The purpose of the descriptive qualitative method is to give an actual explanation descriptively. Based on those definitions, it can be said that a descriptive qualitative method is a method that can be used to explain and analyze the data using words. The data in this study was analyzed by the following steps. The first step was identifying and classifying the language style that often occurred during the conversation between Tony Stark and other characters in Avengers: Infinity War movie. The next step was to classify the data that had been identified. Then they were classified into the types of language style and their function that used by Tony Stark.

\section{FINDING AND Discussion}

This research focused on the analysis of language style and their function which is used by Tony Stark in Avengers: Infinity War movie. The analysis was done by the theory of language style proposed by Holmes (2004) and function of language proposed by Jakobson in Holmes (2001) as the supporting theory.

a. Standard Language

(A-1)

Tony Stark: I had a dream about it. It was so real.

Pepper Potts: If you wanted to have a kid, you wouldn't have done that.

$(11.23-11.27)$

This scene shows the topic of their conversation getting serious. Tony went back to using standard language when speaking to Pepper Potts and began to weigh down his voice. The sentences that he used are arranged grammatically and following a good and correct simple past tense (Subject + verb $2+$ Object). The simple past tense is used to describe an event that happened in the past. In English, the simple past is the most basic form of the past tense. The action may take place in the near past or the distant past, and the length of the action is unimportant.

This sentence has a referential function that aims to convey information and statement from the speaker to the listener. In this case, Tony Stark wants to convince Pepper Pots about his dream. He wants his girlfriend to listen and believe in him. Therefore, his utterance fulfilled the purpose of the referential function.

Pepper Potts: [Insistently] You don't need that.

Tony Stark: I know. I had the surgery. I'm just trying to protect us. The future uses, and that's it. Just in case there's a monster in the closet, instead of, you know...

$(11.50-12.00)$

In the same scene, Tony Stark still uses standard language. The word structure and sentences are following good and correct grammar. This indicates that the language used is under the standard and codified and has an official status which is a common feature of the standard language (Holmes: 2004). It is shown from the sentence I'm just trying to protect us shows that he uses the present continuous tense which has been standardized in English. The present continuous (also known as present progressive) is a verb tense used to indicate that an ongoing event is taking place right now, either in the moment of expression or in the broader context. The present continuous can also be used to 
suggest that something will happen in the immediate future. In this case, Tony Stark's utterance means that he always protects himself and his girlfriend from danger. As a result, it can be called if Tony Stark uses standard language to show its serious thing.

Based on the explanation before, Tony Stark's utterance uses an expressive function. Following the purpose of the expressive function, which is to convey the emotions and feelings of the speaker. In this utterance, Tony Stark shows his love by protecting Pepper Potts from all dangers. Based on that explanation, Tony Stark's utterance fulfilled the characteristic of expressive function.

b. Vernacular Language (B-1)

Bruce Banner: Okay, guys, could we table this discussion right now? The fact is that we have this Stone. We know where it is. Vision is out there somewhere with the Mind Stone, and we have to find him now.

Tony Stark: [Awkwardly] Yeah, that's the ... thing.

$$
(14.49-14.52)
$$

The scene continues and shows Bruce Banner asking about the whereabouts of Vision, a technology created by Bruce Banner and Tony Stark. Tony Stark is seen using vernacular language to express his confusion when Bruce Banner asks him to look for Vision. This can be seen in the use of the word "yeah" which can be interpreted as yes in the standard language. The word falls into the category of vernacular language markers because it does not have official status in English. However, it is commonly used in everyday conversation by various groups ranging from children, adolescents, adults, and even the elderly.

Because the utterance serves to express Tony Stark's confusion over the existence of Vision, the utterance has an expressive function. Expressive function means that specific or to express the speaker's emotions (Jakobson in Holmes: 2004). The purpose of the expressive function is to convey the feelings and emotions of the speaker to convey it to the listener.

Peter Parker: Hey, man. What's up, Mr. Stark?

Tony Stark: Kid, where'd you come from?

Peter Parker: Field trip to MoMA.

$$
(21.40-21.43)
$$

The scene resumed when Spiderman or Peter Parker were going on a school field trip, but because on the way, he saw the commotion that was happening he immediately caught up with Tony Stark and helped him. When Spiderman approaches him, Tony Stark greets him and asks Peter Parker to use the vernacular language style. He uses the word kid to call Peter Parker. This is because Tony Stark has a close relationship with Peter Parker like his own brother, which is why he uses the word kid to call him instead of Peter. That way, one of the characteristics of the vernacular language style has been fulfilled, namely using a nickname or first name for people who have a fairly close relationship. This is the opposite of the characteristic standard language which requires a person to use the last name to address someone else for politeness and respect for that person.

Because Tony Stark was surprised to see Peter Parker coming among the noise that was happening on the streets, he asked a question to just say hello to Peter Parker. An utterance from Tony Stark has an expressive function that aims to convey the emotions and feelings of the speaker, in this case, Tony Stark himself. This refers to the expressive function because Tony Stark had a feeling of surprise and was quite helped by the arrival of Peter Parker in his battle against Thanos' servants.

\section{CONCLUSION}

This study discussed the language style and its functions used by Tony Stark Avengers: Infinity War movie. The 19th series by the Marvel Cinematic Universe, which is officially broadcast by Disney+ Hotstar Indonesia was taken as the data in this study. Based on the results of the analysis from the previous chapter, it can be concluded that Tony Stark used two types of language styles to talk to other characters. It is standard language and vernacular language (nonstandard). As a result, in this movie, Tony Stark used more standard language to communicate with his Avengers partners. This movie had a genre of action-science fiction which made Tony Stark face more serious and formal situations. It indirectly the standard language was more dominant than vernacular language. Meanwhile, the vernacular language is only used in certain scenes that had a little bit of comedy, and when Tony Stark talked to characters who were much younger than him (read: Peter Parker).

Based on the results found, Tony Stark uses 5 functions in the language style he uses, they are directive function, expressive function, phatic function, referential function, and poetic function. However, the more dominant functions are the expressive function which aims to express Tony Stark's emotions and feelings, the directive function which aims to ask the listener to do something, and the referential function which aims to provide information in the form of facts and statements of truth.

\section{REFERENCES}

[1] Dewi, Ida Ayu. 2020. Language Style Used by Main Character in Movie Me Before You (thesis). Denpasar: Udayana University.

[2] Cambridge University Press. (n.d.). Slow down. In Cambridge dictionary. Retrieved February 23, 2021. Available

from https:/dictionary.cambridge.org/dictionary/english/slo w-down 
[3] Cambridge University Press. (n.d.). All right. In Cambridge dictionary. Retrieved March 16, 2021. Available from https://dictionary.cambridge.org/dictionary/english/alri ght

[4] Dong, B. 2016. "Formality of the style, maturity or the artist - stylistic analysis in a poem in Joyce's A portrait of the artist as a young man". Theory and Practice in language studies.

[5] Hawkin, Andrew. 2012. Iron Man., (cited in 2012. Available from https://marvelcinematicuniverse.fandom.com/)

[6] Holmes, Janet. 2004. An Introduction to Sociolinguistics. New York: Longman

[7] Keraf, Gorys. 2000. Diksi dan Gaya Bahasa. Jakarta: Pustaka Utama

[8] Meyerhoff, Miriam. 2015. Introducing Sociolinguistics. New Zealand: Taylor and Francis

[9] Rahayu, Ketut Febri. 2018. Language Style Used by Fangirls in Korean Idol Online Community. Denpasar: Udayana University.

[10] Rashid, Siti Khatijah Mat dan Hakim Zainal. 2013. “A Contrastive Study of Language Style al-Tawkid between Malay and Arabic Languages". The National University of Malaysia. Kuala Lumpur

[11] Traffis, Catherine. 2010. Alright or All Right-Which Is Correct? (cited in 2010. Available from https://www.grammarly.com/blog/alright-vs-allright/\#: :text=People $\% 20$ are $\% 20$ often $\% 20$ surprised $\%$ 20to,as $\% 20$ two $\% 20$ words $\% 3 \mathrm{~A} \% 20$ all $\% 20$ right.)

[12] Tololiu, Yunita Gloria. 2017. Language Style With Reference to the Movie Ella Enchanted by Gail Carson Levine (thesis). Denpasar: Udayana University.

[13] Trudgill, Peter. 1974. Sociolinguistic: An Introduction to Language and Society. Switzerland: Penguin books.

[14] Wardaugh, R. 1986. An Introduction to Sociolinguist. Australia: Blackwell Publishing 